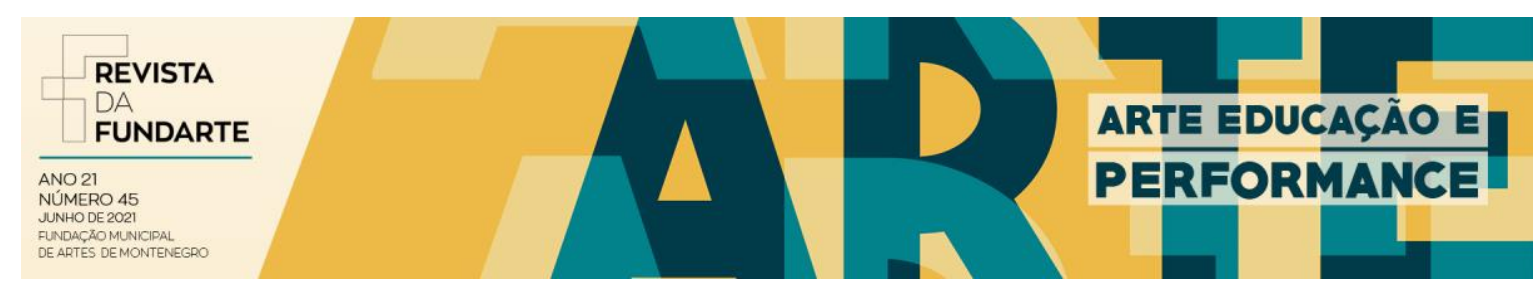

\title{
SOBRE A PROPOSIÇÃO DE UMA PRÁTICA PEDAGÓGICA DO SUJEITO NOMEADO COMO ARTISTA-PROFESSOR
}

\author{
Lislaine Sirsi Cansi
}

DOI: $10.19179 / 2319-0868 / 777$

CANSI, Lislaine Sirsi. Sobre a proposição de uma prática pedagógica do sujeito nomeado como artista-professor. Revista da FUNDARTE. Montenegro, p.01-14, ano 21, oㅡ 45, junho de 2021.

Disponível em: http://.seer.fundarte.rs.gov.br/index.php/revistadafundarte/index> 30 de junho de 2021. 


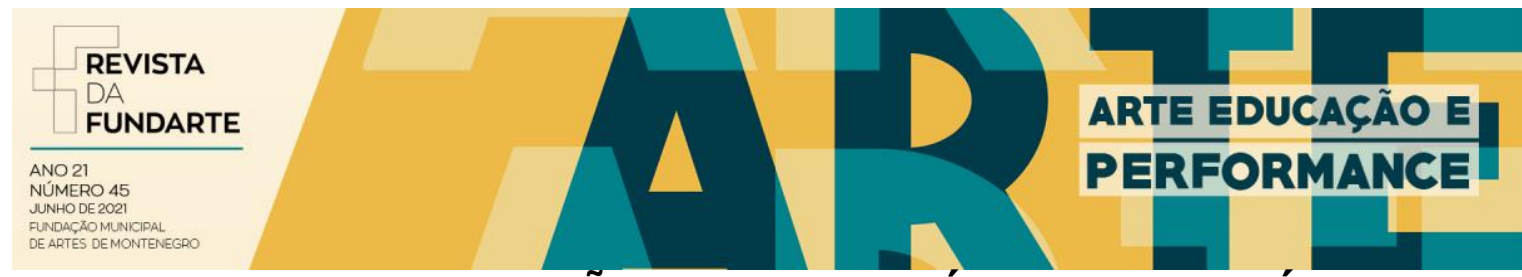 \\ SOBRE A PROPOSIÇÃO DE UMA PRÁTICA PEDAGÓGICA DO SUJEITO NOMEADO COMO ARTISTA-PROFESSOR
}

Lislaine Sirsi Cansi ${ }^{1}$

\begin{abstract}
Resumo: $O$ presente artigo compõe-se em uma escritura narrativo-reflexiva. $O$ artista-professor, sujeito que protagoniza a história, observa o universo escolar e propõe uma prática pedagógica para o Ensino da Arte. A proposição de ordem reflexiva e voltada para a sala de aula escolar advém de certa experiência do artista-professor com sua poética. Dessa experiência, a categoria "corpo" norteia a proposta pedagógica. Autores como Félix Guattari (2012), Gilles Deleuze (1992), Jorge Larrosa (2015), John Dewey (2010) e Katia Canton $(2001 ; 2004 ; 2012)$ fundamentam o pensamento do artista-professor.
\end{abstract}

Palavras-chave: Artista-professor; Prática pedagógica; Corpo.

\section{ON THE PROPOSITION OF A PEDAGOGICAL PRACTICE OF THE SUBJECT APPOINTED AS ARTIST-TEACHER}

\begin{abstract}
The present article is composed in a narrative-reflexive writing. The artist-teacher, the subject that leads the story, observes the school universe and proposes a pedagogical practice for the Teaching of Art. The proposition of a reflective order and focused on the school classroom comes from a certain experience of the artist-teacher with his poetics. From this experience, the category "body" guides the pedagogical proposal. Authors such as Félix Guattari (2012), Gilles Deleuze (1992), Jorge Larrosa (2015), John Dewey $(2010)$ and Katia Canton $(2001 ; 2004 ; 2012)$ support the artistprofessor's thinking.
\end{abstract}

Keywords: Art teaching; Pedagogical practice; Body.

\section{Introdução}

Sabemos que escrever um texto e também o momento anterior a esta ação é, para muitos de nós, pesquisadores ou não, um ato sofrível. Para aquém desse momento, digo, até chegarmos ao produto final, ao texto "acabado", denso, aquele que diz algo para alguém, passamos por diferentes fases. O passo a passo textual constrói-se pluralmente, mesmo que fisicamente o autor esteja só, desde a estruturação de ideias, a articulação daquilo que há em nosso interior, nossas

\footnotetext{
1 Bacharelado e Licenciatura em Desenho e Plástica: Artes Visuais (UFSM)

Especialização em Artes Visuais: Cultura e criação (SENAC/RS)

Mestrado em Artes Visuais (PPGAV/UFPel)

Doutoranda em Educação (PPGE/UFPel), bolsista CAPES
}

CANSI, Lislaine Sirsi. Sobre a proposição de uma prática pedagógica do sujeito nomeado como artista-professor. Revista da FUNDARTE. Montenegro, p.01-14, ano 21, oㅡ 45, junho de 2021.

Disponível em: http://.seer.fundarte.rs.gov.br/index.php/revistadafundarte/index> 30 de junho de 2021. 


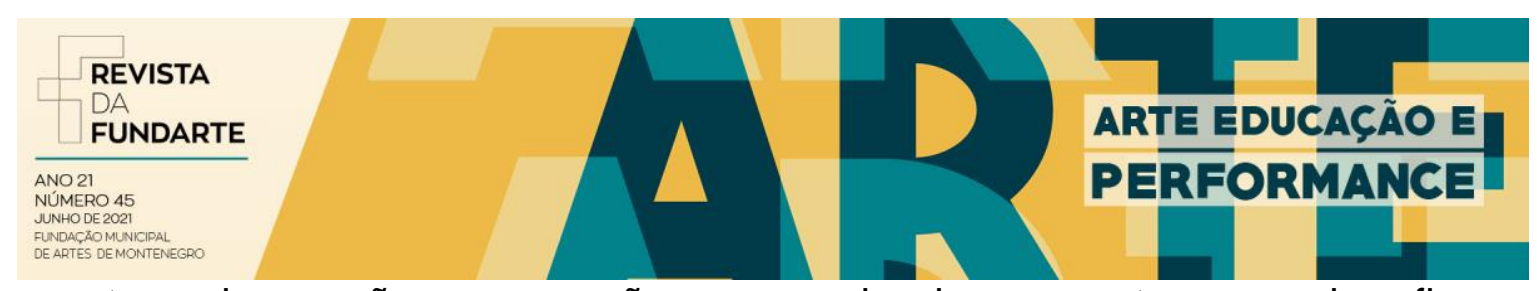

escutas, observações, percepções, e os desvios no outro - aqui, refiro-me à fundamentação teórica de nossas pesquisas sendo obviamente os conceitos de pensadores e também os mais diversos objetos estéticos em se tratando de pesquisas em/sobre/com arte, a busca da palavra mais adequada, o desejo de compor a "escritura" (BARTHES, 2005), como se compõe uma tela em branco de um pintor que, com estilo singular pinta, fazendo da tela um transbordar de vida, até certas ações corporais, senão apelos gestuais, do autor frente o texto que, aos poucos, se desenvolve.

A inquietação existente em mim no processo de "escritura" fez de meu corpo seu presidiário. Havia um turbilhão de ideias, lembranças, referências em meu pensamento, porém sentia meu corpo preso, inerte, como se estivesse em um cárcere, solitário, sem objetos para poder transformar em "marca" as palavras, até então confusas, de minha mente. Nesse momento e já pertencente a uma história, imagino-me como um personagem, assim me distancio da prisão em que habitava meu corpo, oprimido pelas regras de um sistema autoritário. A partir daqui assumo tal personagem objetivando que meu corpo permita a passagem de meu pensamento para as folhas que, neste ponto, já não se encontram totalmente em branco.

$\mathrm{Na}$ tentativa de sair do cárcere, meu corpo transita por diferentes lugares: percorre cômodos de uma casa, observa o que há por detrás das cortinas, toma para si alguns objetos quando, de repente, soa um bip do aparelho celular. Trata-se de um aviso: havia chegado um e-mail na caixa de mensagens eletrônicas. Ao corpo do e-mail se lia apenas o link da Revista da FUNDARTE, condizente a sua trigésima edição intitulada Arte, Práticas Pedagógicas e Pesquisa (2015)². É perceptível que meu personagem, há passos largos daquele cárcere, estava deambulando a procura de algo para desvelar; agora, a palavra "Práticas", escrita com a letra $p$ em maiúsculo, levaria meu corpo à imersão de outra história, a alguma história na qual a palavra "Práticas" seria o agente diferencial.

Ao passar os olhos no sumário da referida revista, percebi a amplitude e a

\footnotetext{
2 Disponível em: <http://seer.fundarte.rs.gov.br/index.php/RevistadaFundarte/issue/view/46/showToc>, acesso em: 28 out. 2016.
}

CANSI, Lislaine Sirsi. Sobre a proposição de uma prática pedagógica do sujeito nomeado como artista-professor. Revista da FUNDARTE. Montenegro, p.01-14, ano 21, oㅡ 45, junho de 2021.

Disponível em: http://.seer.fundarte.rs.gov.br/index.php/revistadafundarte/index> 30 de junho de 2021. 


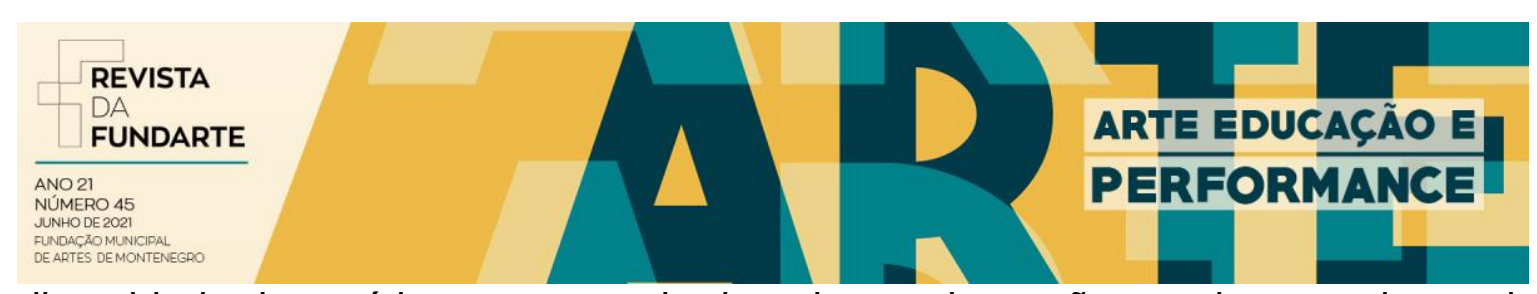

diversidade das práticas para a sala de aula escolar e não escolar e, mais que isso, a necessidade de proposições fundamentadas para que os estudantes possam refletir - e não apenas descrever, acerca de seu mundo e do mundo ao redor. Mergulhei, particularmente, nos textos de Simões (2015), Capra (2015) e de Pacheco (2015), referentes ao campo da arte. Em Simões (2015), interessei-me sobre a problematização do que é o contemporâneo. Em Capra (2015), acerca da compreensão do conceito da imagem no espaço educacional: "Dizer que as imagens tocam o real é para considerar que nesse contato, inflamam-se. As imagens ardem, pois algo Ihes acontece, o "com tato" as energiza e as alimenta de uma potência única. " (CAPRA, 2015, p. 77) ${ }^{3}$. Por fim, em Pacheco (2015), atentei-me sobre a possibilidade de propor as ações educacionais como atos de criação. Confesso que não foi difícil encontrar o caminho que levou meu personagem ao espaço escolar.

No caminho até a escola, refleti sobre Práticas: palavra nobre (já que apresentada com p maiúsculo), escrita no plural e determinada por certo anexo, Pedagógicas. Práticas Pedagógicas, eis a expressão que levaria meu personagem a viajar por diferentes lugares, mesmo estando restrito a caminhar somente naquela rua que o conduziria à escola. Imediatamente inserido no espaço escolar meu personagem observa as práticas do cotidiano realizadas pelos alunos a partir da oferta de alguns professores. Não é preciso estar na frente dos muros que encobrem a escola para perceber as mazelas de algumas práticas, inclusive aquelas que concernem à criação e à reflexão em/sobre/com arte e que cotidianamente furtam os desejos de os alunos permanecerem prazerosamente na escola. Meu personagem choca-se com essa brutal realidade escolar e não hesita em relacionar a escola àquele lugar já experimentado, àquele lugar em que se encontrava aprisionado, àquele lugar no qual seu corpo, inquieto, não tinha permissão para relacionar-se com seu pensamento. Considerando tais questões, meu personagem se apropria de um ser apequenado neste mundo negativo da escola, o artista-professor. Entendo que esse personagem, o artista-professor, não necessariamente possui formação como artista, mas necessariamente é criativo e reflexivo como um artista, na construção e reflexão de sua prática docente. Nesse caso, torna-se necessário que

${ }^{3}$ Pensamento estruturado a partir da obra de Georges Didi-Huberman.

CANSI, Lislaine Sirsi. Sobre a proposição de uma prática pedagógica do sujeito nomeado como artista-professor. Revista da FUNDARTE. Montenegro, p.01-14, ano 21, oㅡ 45, junho de 2021.

Disponível em: http://.seer.fundarte.rs.gov.br/index.php/revistadafundarte/index> 30 de junho de 2021. 


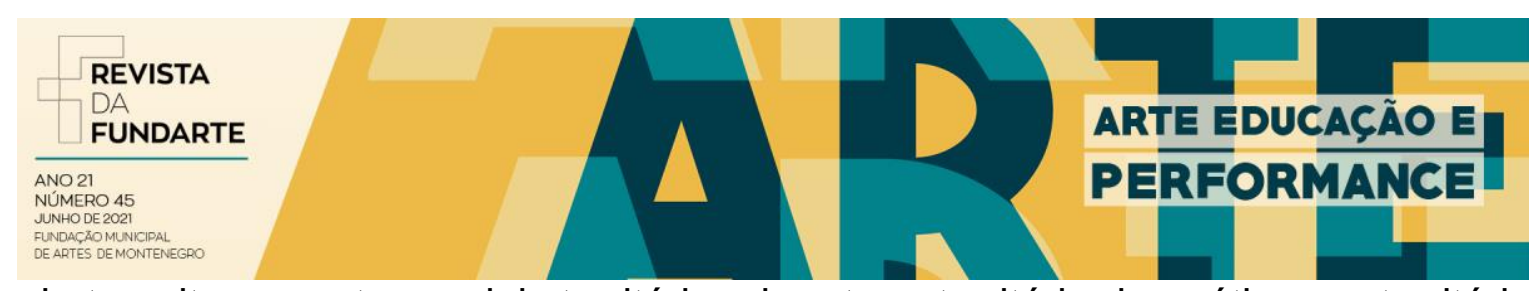

ele transite por entre os dois territórios da arte, o território da poética e o território do ensino. A partir desse momento, o artista-professor se intitula como protagonista dessa história.

O artista-professor, presente no universo da referida escola, olha atentamente para os alunos que se encontram nesse espaço que às vezes aprisiona e, considerando a palavra Práticas, problematiza a relação ensino-aprendizagem e se pergunta: como é possível ensinar arte e como é possível aprender arte na escola? E mais, o artista-professor relaciona tais questões à poética na docência e pensa na possibilidade de aproximar o "pensamento da arte" à sala de aula escolar (CANSI, 2016).

Nesse contexto, o artista-professor sugere, a partir de Larrosa (2015), que pode ser a "experiência" a palavra fundamental para ressignificar a relação desses alunos ora "sem corpo" com tal espaço consideradas a "experiência" do artistaprofessor para ensinar e a "experiência" do aluno para aprender. Assim, proponho uma prática pedagógica criadora advinda da própria "experiência" do artistaprofessor e não referente a uma teoria, a um método específico ou às questões da História da Arte. Nesse caso, uma prática docente determinantemente instigada por questões da própria prática artística do artista-professor, isto é, questões advindas de seu pensamento ao experimentar sua poética, em específico, o corpo. Aos alunos, a proposição se dá na criação e reflexão artística a partir de questões que envolvem a categoria 'corpo'. Dessa forma, o artista-professor acredita que os estudantes se envolveriam com "modos de arte", com o "pensamento da arte".

A fundamentação teórica do trabalho do artista-professor se estrutura a partir do paradigma estético de Félix Guattari, do pensamento sobre a sociedade de controle de Gilles Deleuze, de questões que envolvem "experiência", de Jorge Larrosa, e de John Dewey, sobre a categoria 'corpo', Katia Canton e, mais largamente integrada às reflexões do Grupo de Pesquisa Artefatos para Leitura e construção do 'pequeno território', coordenado pela professora Renata Azevedo Requião, junto ao Programa de Pós-Graduação em Artes Visuais (PPGAV/UFPel).

\section{Da observação do universo escolar à proposição da prática pedagógica}

CANSI, Lislaine Sirsi. Sobre a proposição de uma prática pedagógica do sujeito nomeado como artista-professor. Revista da FUNDARTE. Montenegro, p.01-14, ano 21, oㅡ 45, junho de 2021.

Disponível em: http://.seer.fundarte.rs.gov.br/index.php/revistadafundarte/index> 30 de junho de 2021. 


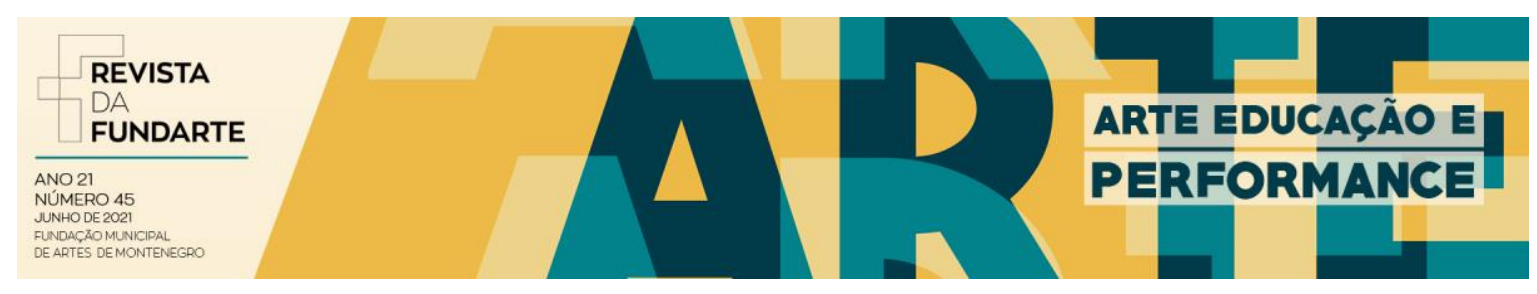

O artista-professor observa cuidadosamente o universo escolar. Tomado por tal função, percebe o drama pelo qual passam os alunos ao atenderem (ou não) algumas práticas conduzidas por seus professores. Em contrapartida, seu olhar, do artista-professor, acompanha a frustração desses professores ao confrontar-se com o resultado (muitas vezes negativo) de suas práticas. Percebe, então, algo que promove esse enfrentamento: o "controle" e a falta de sentido no ensinoaprendizagem.

Nesse contexto, e antes de qualquer ação é preciso pensar sobre a estrutura do ambiente escolar, sobre como funciona seu sistema, sobre como é esse espaço na contemporaneidade, sobre os sujeitos que lá se encontram, bem como de onde eles vêm, para onde vão e como são, se portam, pensam, agem e, sobretudo, quais são os seus desejos.

Partindo do primeiro item dessa reflexão, a estrutura do ambiente escolar, nos damos conta de que a escola se fecha à comunidade através de seus muros, algo que remete diretamente ao medo e a insegurança que atravessa a cidade (BAUMAN, 2009). Muitos muros são preenchidos com cor, talvez para amenizar essa fissura entre ela mesma e a sociedade. Tal fissura nos leva para o segundo item: o sistema escolar. O muro ao redor da escola afasta (para não dizer proíbe) olhares de dentro para fora e de fora para dentro. Os estudantes inseridos no espaço escolar não se relacionam com o mundo exterior a ele, a presença do muro aparenta ser um elemento simbólico para a normativa do não: o que pertence ao mundo de fora ficará fora da escola. O corte, portanto, determina que aquilo que se encontra externamente não pode ser o mesmo que se encontra em seu interior. $O$ sistema murado da escola corta relações com a vida que continua a existir no lado de fora e fabrica outras vidas para aqueles que permanecem, mesmo que essa permanência seja apenas por algumas horas. A escola torna-se um mundo a parte. O objetivo, nesse sentido, não seria a confinação, mas, nas entrelinhas, um "modo de controle". Controlam-se entradas e saídas por entre o muro, nas salas de aula e demais espaços da escola. Controla-se o ponto dos funcionários, bem como a frequência dos estudantes. Controla-se a merenda escolar. Controla-se o uso de

CANSI, Lislaine Sirsi. Sobre a proposição de uma prática pedagógica do sujeito nomeado como artista-professor. Revista da FUNDARTE. Montenegro, p.01-14, ano 21, oㅡ 45, junho de 2021.

Disponível em: http://.seer.fundarte.rs.gov.br/index.php/revistadafundarte/index> 30 de junho de 2021. 


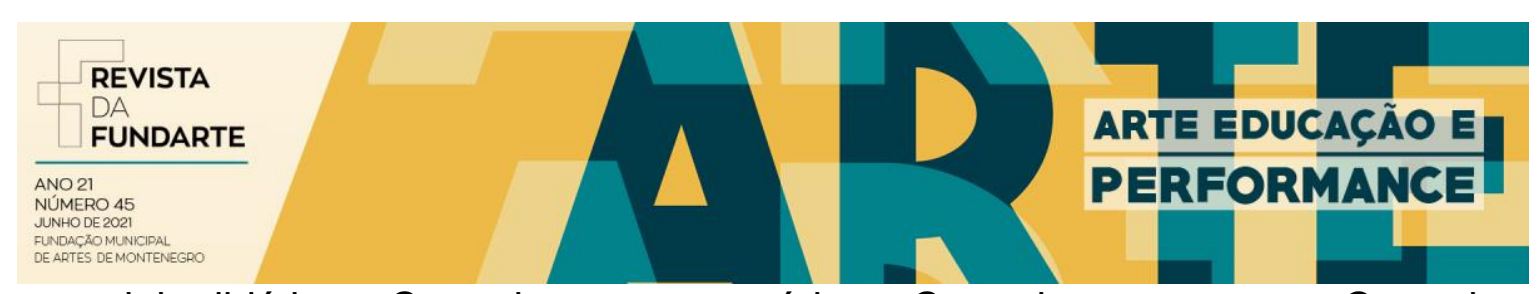

material didático. Controlam-se conteúdos. Controlam-se notas. Controlam-se métodos de avaliação. Controla-se a formação docente e discente. Controlam-se as vestimentas. Controlam-se identidades e formas de expressão. Há um controle brutal, capitalista, "contínuo e ilimitado" (DELEUZE, 1992) no espaço escolar e, por tudo isso, não raras vezes, os sujeitos não são percebidos na escola, muito menos os seus desejos.

A escola não é mais, segundo Deleuze (1992, p. 224), "espaço analógico distinto que converge para um proprietário, Estado ou potência privada", mas é agora "figura cifrada, deformável, transformável" que segue o modelo de empresa. A escola busca números, índices, mérito. A escola busca produção, produção, produção e o tarefismo se torna permanente, mesmo que sem sentido. Deleuze (1992, p. 220), ao refletir sobre as diferenças entre as sociedades disciplinares ("espaços de confinamento") e a sociedade de controle ("modos de controle"), afirma que "Não cabe temer ou esperar, mas buscar novas armas".

O artista-professor, considerando a tomada de iniciativa sugerida por Deleuze, preocupado com certas práticas observadas no cotidiano escolar e com a incorporação dos estudantes ao sistema escolar controlador, levanta questões sobre ensino-aprendizagem em/sobre/com arte. Como "nova arma", o artista-professor poderia pensar aqui na tentativa de transformar as práticas do cotidiano escolar em "Práticas", com a letra p escrita em maiúsculo, cogitando que tal marcação poderia ser o diferencial na ação pedagógica através da experiência - aquilo que se entope de sentido, já que a experiência não padroniza (objetivo da escola-empresa capitalista), mas singulariza. O paradigma estético de Guattari (2012) discute sobre processos de subjetivação nos quais o sujeito é "desnaturalizado" para então enfrentar outros territórios e constituir-se em outra subjetividade. Nesse contexto, Bourriaud (2009, p. 135) explica que "para Guattari, o paradigma estético deveria contaminar todos os registros do discurso, inocular o veneno da incerteza criativa e da invenção delirante em todos os campos do saber". Logo, no agir do artistaprofessor o paradigma estético funcionaria como suporte para as "Práticas" tomarem corpo.

CANSI, Lislaine Sirsi. Sobre a proposição de uma prática pedagógica do sujeito nomeado como artista-professor. Revista da FUNDARTE. Montenegro, p.01-14, ano 21, oㅡ 45, junho de 2021.

Disponível em: http://.seer.fundarte.rs.gov.br/index.php/revistadafundarte/index> 30 de junho de 2021. 


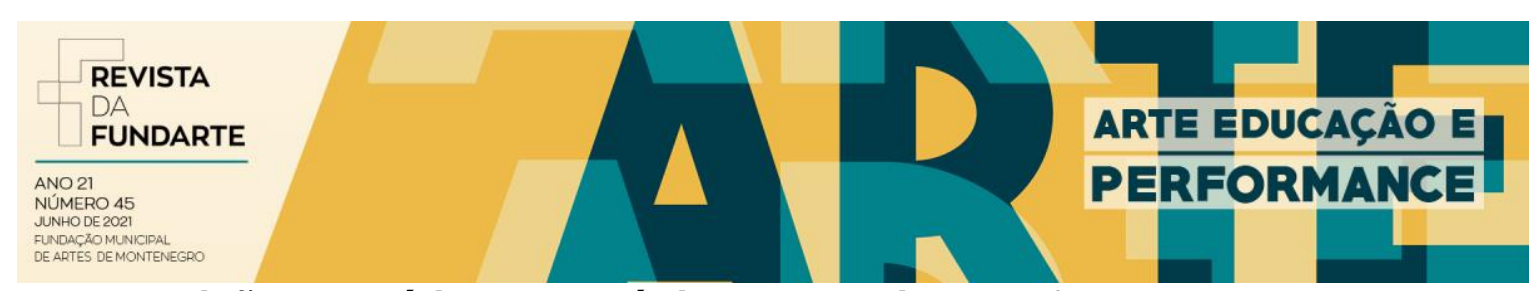

A proposição da prática pedagógica pelo artista-professor

Dá-se a entender pelas observações do artista-professor que no espaço escolar coisas são passadas para que coisas aconteçam (ou não). De acordo com Larrosa (2015, p. 18) "A experiência é o que nos passa, o que nos acontece, o que nos toca. Não o que se passa, não o que acontece, ou o que toca". Trata-se "[...] de uma experiência singular" (DEWEY, 2010). Nesse contexto, a "experiência" torna-se algo raro na escola já que ela não se denomina como informação, como opinião ou como trabalho.

\begin{abstract}
A experiência, a possibilidade de que algo nos aconteça ou nos toque, requer um gesto de interrupção, um gesto que é quase impossível nos tempos que correm: requer parar para pensar, parar para olhar, parar para escutar, pensar mais devagar, olhar mais devagar, e escutar mais devagar; parar para sentir, sentir mais devagar, demorar-se nos detalhes, suspender a opinião, suspender o juízo, suspender a vontade, suspender 0 automatismo da ação, cultivar a atenção e a delicadeza, abrir os olhos e os ouvidos, falar sobre o que nos acontece, aprender a lentidão, escutar aos outros, cultivar a arte do encontro, calar muito, ter paciência e dar-se tempo e espaço. (LARROSA, 2015, p. 25).
\end{abstract}

Interromper-se no tempo e no espaço para poder respirar profundamente e pensar demoradamente (também com os olhos e os ouvidos), eis a questão para professores e para alunos em se tratando da proposição ensino-aprendizagem levantada pelo artista-professor. Ter o privilégio de parar por um instante, é dar-se mais tempo que o tempo cronológico pontua no relógio: é abrir-se para a experiência, é sentir no corpo o que está the passando, the acontecendo, the tocando. Salienta-se que parar por um instante é um privilégio, pois o tempo na contemporaneidade é preenchido com milhares de tarefas de ordem contínua, desse modo é fundamental concordar com Deleuze (1992), ao afirmar que agora não terminamos nada. Mesmo com o enfrentamento do que nos fez parar, nos distanciar socialmente, nos isolar do mundo, a pandemia causada pela COVID-19, continuamos atolados no produtivismo, nas tarefas advindas de todas as ordens. Talvez, nesse momento, o privilégio da experiência tenha se tornado presença no cotidiano, e aqui, não vou me deter à profundidade e urgência de pensar sobre isso, pois, penso, agora, que o privilégio da experiência também depende do acesso às oportunidades, bastante desigual em nosso país.

CANSI, Lislaine Sirsi. Sobre a proposição de uma prática pedagógica do sujeito nomeado como artista-professor. Revista da FUNDARTE. Montenegro, p.01-14, ano 21, oㅡ 45, junho de 2021.

Disponível em: http://.seer.fundarte.rs.gov.br/index.php/revistadafundarte/index> 30 de junho de 2021. 


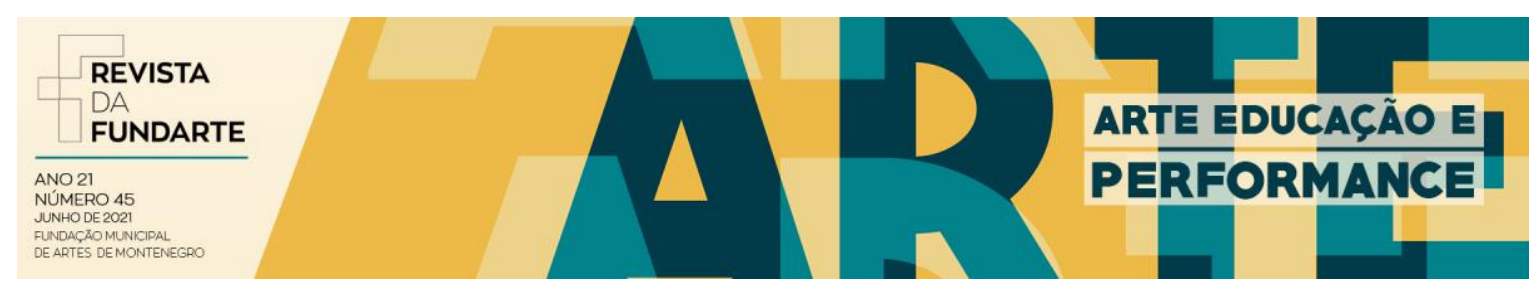

Avançando: o artista-professor faz esse experimento de interrupção no tempo e no espaço. Ele que aqui produz uma poética, para nesse momento poder observála, analisá-la, senti-la. Faz uma pausa no seu tempo de produção para ter a possibilidade de percebê-la, não no sentido de fabricar certa experiência em relação a essa produção, pois segundo Larrosa (2015) a experiência não se fabrica, mas intentando captar algo (qualquer verbo aqui parece inapropriado, considerando que a experiência nos deixa mudos quando nos servimos dela), através dessa passividade, a partir de sua receptividade, de sua disponibilidade e abertura. Com essa abordagem o artista-professor assume o corpo como categoria que "Ihe passa, Ihe acontece, Ihe toca" e ao passar, ao acontecer e ao tocar esse corpo, também o forma e o transforma.

Formar e transformar: palavras caras no/para o espaço escolar. Formar sem transformar implica em pôr na forma, idealizar, padronizar e permanecer no cárcere (aquele, do começo desse texto e que desejei me distanciar). Acredito que transformar seja a palavra mais genuína para esse lugar, pois é ela que dá margem a novas possibilidades de ver, ler, ouvir, perceber o mundo para então ressignificá-lo.

Ao processo de formar e transformar, o artista-professor inclui as palavras criar e refletir. Ele pensa que é preciso acionar processos de desejo nos alunos através de modos de fazer diferente. E, ao considerar que existem inúmeras possibilidades de enxergar e enxergar-se no mundo, o artista-professor propõe a categoria que "Ihe passou, Ihe aconteceu, Ihe tocou": o corpo.

Corpo: do texto, da casa. Corpo-coletivo. Corpo-casa. Corpo-sujeito. Corpoobjeto. O corpo social. O corpo físico. O corpo químico. O corpo carne. O corpo morto. O corpo vivo. O corpo emocional. O corpo engravidado. O corpo como experimento. O corpo que abriga, que sente, que sonha, que veste, que se transforma. O corpo nu. O corpo do homem, da mulher, da criança, do idoso, dos animais. O corpo que fala, que expressa e que esconde e se esconde. $O$ corpo que identifica: uma identidade, uma etnia, uma raça, uma idade. O "corpo-próprio": quando o corpo é o sujeito da percepção, logo, o conhecimento se dá pelos sentidos (MERLEAU-PONTY, 1990). O “corpo-sem-órgãos”, segundo Deleuze e Guattari (2012, p. 12), "não é uma noção, um conceito, mas antes uma prática, um conjunto

CANSI, Lislaine Sirsi. Sobre a proposição de uma prática pedagógica do sujeito nomeado como artista-professor. Revista da FUNDARTE. Montenegro, p.01-14, ano 21, oㅡ 45, junho de 2021.

Disponível em: http://.seer.fundarte.rs.gov.br/index.php/revistadafundarte/index> 30 de junho de 2021. 


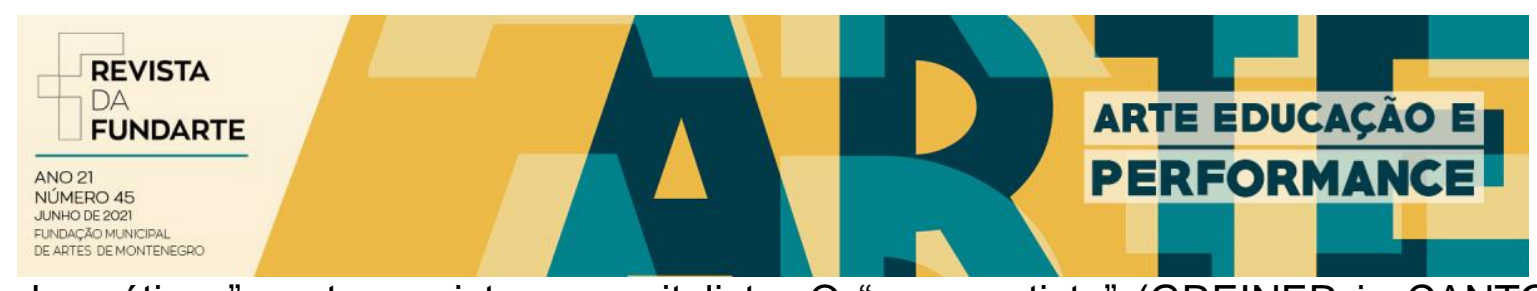

de práticas" contra o sistema capitalista. O "corpo-artista" (GREINER in CANTON, 2009), o corpo que desestabiliza a idealização do corpo. Canton (2009, p. 25) compreende que a potência do "corpo-artista" está "na forma como ele ajudaria a humanidade a se alimentar de conhecimentos com base na desestabilização de antigas certezas". Por fim, o corpo estético. O corpo na arte. O corpo como arte (CANSI, 2016).

O parágrafo descrito anteriormente tomou forma através do excesso e da repetição, justamente porque se compreende que a palavra corpo se relaciona com várias áreas do conhecimento. Dessa forma, a redundância não se integra àquela marcação: embora repetitiva, a palavra corpo assume diferentes significados e por isso se desdobra em muitos sentidos.

É nesse contexto que o artista-professor dá continuidade a sua reflexão concernente à "Prática". Ele pensa em diferentes sentidos que advém da palavra corpo e assim oferece opções para que os estudantes possam experimentar-se nelas e irem, com o seu corpo, para algum lugar através de momentos de discussão e reflexão. Discutir sobre o corpo implica em falar de dentro, das memórias de um corpo que sente, que vê, que lê, que percebe, e não de sua superfície. A experimentação em outros territórios nesse campo de discussão alimenta a subjetividade do estudante (e também do professor), visto que o processo de subjetivação, segundo o paradigma estético de Guattari (2012), é caótico, é heterogêneo e se molda através da alteridade. Assim, o meio cultural, incluindo aqui a educação e a arte, é um importante "fluido" para compor a produção de subjetividade (BOURRIAUD, 2009).

Em seguida, o artista-professor, ao considerar a experiência estética um dos elos para aproximar o "pensamento da arte" à sala de aula escolar, faz referência a obras de artistas contemporâneos ou não que utilizam o corpo humano como conceito para embasar suas obras. Aqui, ressalto três livros de Kátia Canton que tratam sobre o tema corpo e que poderiam ser explorados na sala de aula escolar: Corpo, identidade e erotismo (2009), Espelho de artista (2001) e Beijo de Artista (2012).

Em Corpo, identidade e erotismo, a autora (2009) apresenta diversos temas

CANSI, Lislaine Sirsi. Sobre a proposição de uma prática pedagógica do sujeito nomeado como artista-professor. Revista da FUNDARTE. Montenegro, p.01-14, ano 21, oㅡ 45, junho de 2021.

Disponível em: http://.seer.fundarte.rs.gov.br/index.php/revistadafundarte/index> 30 de junho de 2021. 


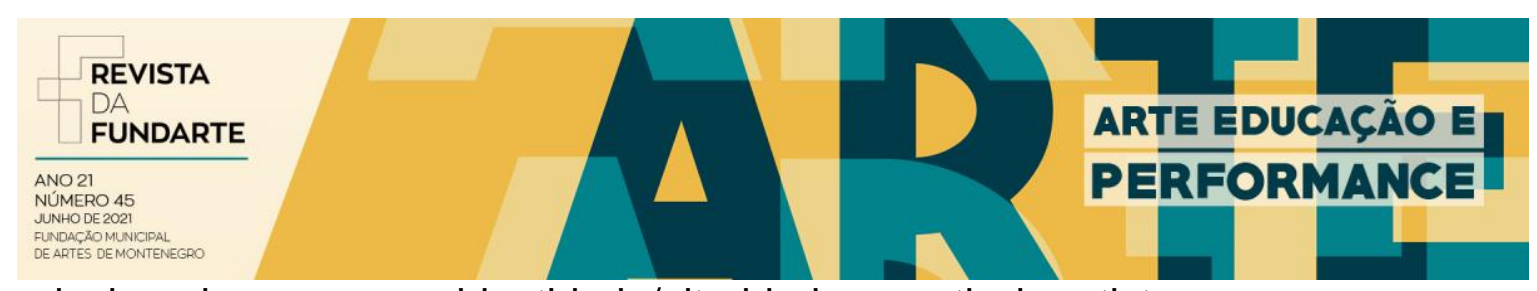

relacionados ao corpo: identidade/alteridade a partir de artistas que usam seu corpo como representação; corpo como sujeito/objeto que "desestabiliza certezas" - o "corpo-artista", corpo como suporte (de linguagens artísticas, de objetos, de vestimentas e adornos corporais), corpo como simulacro (da dor, da deformação, da violência, do sofrimento), corpo e erotismo e corpo, pele e transcendência.

No livro Espelho de Artista, Canton (2004) mostra o tema autorretrato como o "espelho do artista" a partir de uma breve história do autorretrato, e, através de diferentes produções de diversos artistas aponta para questões particulares em cada obra, como a expressão, a forma, o estilo, a linguagem artística, o momento histórico, o material utilizado e a liberdade de criação dos autorretratos.

Já, em Beijo de Artista, a autora discorre sobre vários artistas para expor o tema vinculado ao corpo, o beijo. Utilizando a mesma metodologia de Espelho de Artista, Canton (2012, p. 5) apresenta cenas de beijo associado à história, "localizadas em um contexto de cores, traços, modos de pintar e de esculpir, refletem uma época, um estilo, um jeito de fazer arte que é próprio do artista e de seu tempo".

Nos três livros inúmeras imagens são apresentadas. Elas estão presentes e não poderiam ser negligenciadas. Capra afirma que:

Há um profundo valor na persistência das imagens, que aqui não se refere à preservação de documentos ou de antiguidades, mas da possibilidade de contato com um conhecimento que está latente. Imaginação, montagem e não saber são formas de tocar as imagens e, quem sabe, arder com elas. (CAPRA, 2015, p. 78).

Nesse sentido, é necessário problematizar as imagens, considerando questões intrínsecas a elas, pertencentes ou não ao universo da arte contemporânea. Além disso:

Para que uma imagem renove o pensamento e dê algo a conhecer em processos educativos, é preciso criar condições para saber-se olhado e concernido, habitando os espaços vazios da imagem durante um tempo (como o modelo habitava o tempo da pose da foto antiga). Se pudermos penetrar nessas fendas, poderemos superar a crença irrestrita na visão, na representação e na supremacia da linguagem sobre o olhar. (CAPRA, 2015, p. 80).

CANSI, Lislaine Sirsi. Sobre a proposição de uma prática pedagógica do sujeito nomeado como artista-professor. Revista da FUNDARTE. Montenegro, p.01-14, ano 21, oㅡ 45, junho de 2021.

Disponível em: http://.seer.fundarte.rs.gov.br/index.php/revistadafundarte/index> 30 de junho de 2021. 


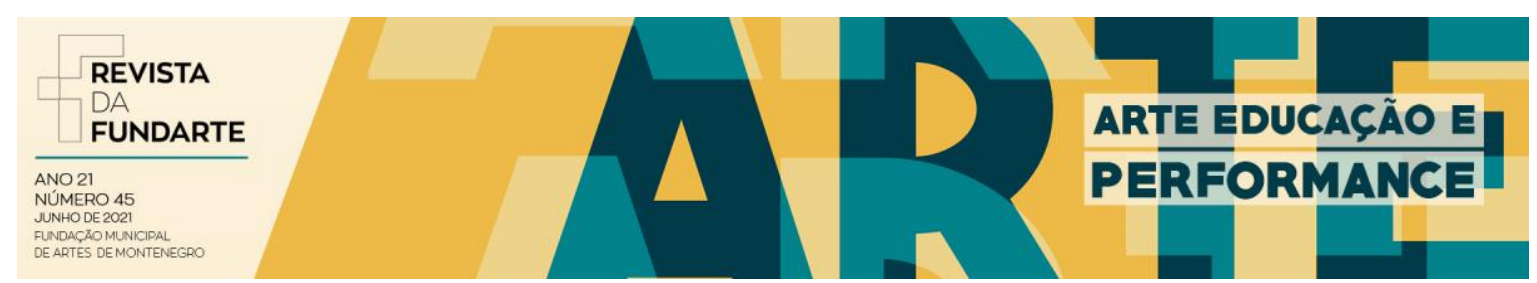

A cognição, nesse momento do agir do artista-professor, seria pautada pela experiência estética do aluno, experiência na qual o aluno se aproximaria do percurso e dos processos dos artistas para poder pensar em seus próprios agenciamentos, para criar e refletir artisticamente, pois o aluno passaria, a partir do que ele vê, a pensar na obra e por decorrência a ampliar sua capacidade de perceber a sua realidade. Dewey (2010) propõe que é possível termos "uma experiência singular", a partir do movimento da vida, isto é, uma refeição, uma viagem, uma conversa. É a relação entre a ação e a sua consequência, afirma Dewey (2010, p. 122), "que confere significado; apreendê-lo é o objetivo de toda compreensão". O corpo, aqui, é a categoria sugerida pelo artista-professor para que o aluno, a partir de uma Prática, tenha uma experiência e assim, possa transformar seu olhar em relação a si e ao mundo.

\section{Considerações finais}

Nesse artigo, o sujeito nomeado como artista-professor, sujeito que transita por entre os dois territórios da arte, o território da poética e o território do ensino, observa o espaço escolar e se choca com o recorte da realidade que vê. Instigado por isso e liberto do cárcere (local em que não sabia como nomear as coisas do mundo), se propõe a pensar sobre a possibilidade de ensinar e aprender na escola, particularmente, no que diz respeito ao campo da arte.

Para isso, ele considera a poética na docência, em que busca aproximar o pensamento da arte à sala de aula escolar. E, assim, a sua proposição de prática pedagógica é realizada através da categoria corpo. Os livros de Canton acionariam os processos de desejo dos estudantes, a partir das inúmeras imagens ali presentes. A cognição mediada pelo artista-professor seria pautada pelos verbos criação e reflexão, considerando o conceito de experiência de Larrosa.

\section{Referências:}

BARTHES, Roland. A preparação do romance. vol. I. São Paulo: Martins Fontes, 2005.

CANSI, Lislaine Sirsi. Sobre a proposição de uma prática pedagógica do sujeito nomeado como artista-professor. Revista da FUNDARTE. Montenegro, p.01-14, ano 21, oㅡ 45, junho de 2021.

Disponível em: http://.seer.fundarte.rs.gov.br/index.php/revistadafundarte/index> 30 de junho de 2021. 


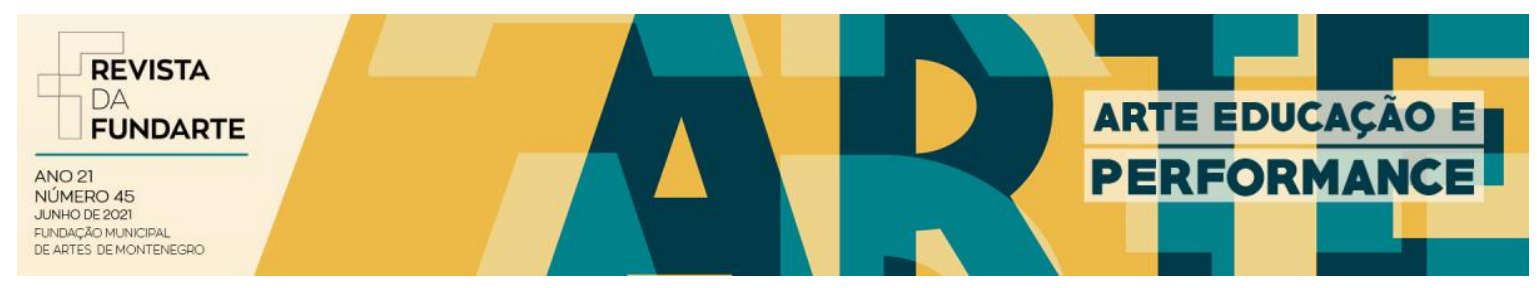

BAUMAN, Zygmunt. Confiança e medo na cidade. Tradução Eliana Aguiar. Rio de Janeiro: Jorge Zahar, 2009.

BOURRIAUD, Nicolas. Estética relacional. São Paulo: Martins, 2009.

CANTON, Katia. Beijo de artista. São Paulo: Cosac \& Naify, 2012.

Corpo, identidade e erotismo. Coleção: Temas da Arte Contemporânea. São Paulo: WMF Martins Fontes, 2009.

Espelho de artista. São Paulo: Cosac \& Naify, 2004.

CANSI, Lislaine Sirsi. Poética na docência [corpo e território]. 2016. $215 f$. Dissertação (Mestrado em Artes Visuais) - Programa de Pós-Graduação em Artes Visuais, Centro de Artes, Universidade Federal de Pelotas, Pelotas, 2016.

CAPRA, Carmen Lúcia. Sobre imagens e contato com imagens. Revista da Fundarte, Montenegro, ano 15, n. 30, p. 73-84, jul./dez. 2015.

DELEUZE, Gilles. Post-Scriptum sobre as sociedades de controle. DELEUZE, Gilles. In Conversações. Tradução de Peter Pál Pelbart. Rio de Janeiro: Editora 24, 1992.

; GUATTARI, Félix. Mil Platôs: capitalismo e esquizofrenia. Vol 3. São Paulo: Editora 34, 2012.

DEWEY, John. Arte como experiência. São Paulo: Martins Fontes, 2010.

GUATTARI, Félix. Caosmose: Um novo paradigma estético. Tradução de Ana Lúcia de Oliveira e Lúcia Cláudia Leão. São Paulo: Editora 34, 2012.

LARROSA, Jorge. Tremores: Escritos sobre experiência. Belo Horizonte: Autêntica, 2015.

MERLEAU-PONTY, Maurice. O primado da percepção e suas consequências filosóficas. Tradução de Constança Marcondes Cesar. São Paulo: Papirus, 1990.

PACHECO, Eduardo Guedes. Arte, diferença e educação - um manifesto sobre formação de professores de arte. Revista da Fundarte, Montenegro, ano 15, n. 30, p. 126-140, jul./dez. 2015.

SIMÕES, Igor Moraes. Sobre luzes, escuros e museologia radical em um breve apontamento acerca do MACRS. Revista da Fundarte, Montenegro, ano 15, n. 30, p. 28-47, jul./dez. 2015.

CANSI, Lislaine Sirsi. Sobre a proposição de uma prática pedagógica do sujeito nomeado como artista-professor. Revista da FUNDARTE. Montenegro, p.01-14, ano 21, ำ 45, junho de 2021.

Disponível em: http://.seer.fundarte.rs.gov.br/index.php/revistadafundarte/index> 30 de junho de 2021. 